\title{
EL IMPACTO DEL CINE EN LAS VANGUARDIAS HISTÓRICAS
}

\author{
ANTONIO ANSÓN \\ Universidad de Zaragoza
}

\begin{abstract}
Trabajo que investiga la manera en que el cine influyó en las formas de la vanguardia histórica. De qué manera son recibidos e interpretados sus recursos formales, cómo esos procedimientos son descifrados y asimilados por los artistas e intelectuales de principios de siglo XX, y de qué modo influyeron y transformaron la estética de vanguardia que fue testigo y se desarrolló de manera simultánea.
\end{abstract}

Palabras clave: Cine; Arte; Pensamiento; Estudios interdisciplinares.

\section{IMPACT OF CINEMA ON THE HISTORICAL ARTISTIC VANGUARDS}

This study investigates the influence of cinema on modernism: the ways in which its formal resources were received and interpreted; how they were deciphered and assimilated by artists and intellectuals at the beginning of the $20^{\text {th }}$ century; and the manner in which they influenced and transformed the aesthetic of concurrently developing avant-garde artistic movements.

Key words: Cinema; Art; Ideas; Interdisciplinary studies.

Si por algo ha de identificarse el arte contemporáneo es por la revolución de carácter visual y tecnológico en la manera de percibir y comunicar qué son la fotografía primero, y el cine inmediatamente después. En ambos casos se trata, tomando prestado el título de Virilio, de "máquinas de ver" que implican una forma inédita de pensar la realidad, de inventarla por tanto, y transformarla a continuación. Fotografía y cine siguieron caminos diversos. Paradójicamente, la fotografía creció y se identificó con el aspecto al que la condenaba Baudelaire negándole su condición de arte: su función documental. El cine, recibido y aclamado como más revolucionario y artístico que la fotografía, se decantó por su perfil más tradicional: la estética naturalista. Ambos, fotografía y cine, forman parte hoy de nuestro bagaje artístico, no sin haber antes renunciado a una parte de su propia identidad. Ambos, también, han ejercido una influencia profunda en la pintura, la escultura y la literatura que se desarrolló al tiempo que fotografía y cine buscaban y encontraban su propia identidad. Esa perspectiva híbrida nos permite componer una toma panorámica de lo sucedido con el sello visual que define el arte del siglo XX.

De los aspectos que pueden agruparse en torno a una caracterización del arte del siglo XX, tal vez sea el cine aquél que ha ejercido una influencia más profunda y extensa. Profunda porque significa la transformación no sólo de presupuestos estéticos, sino también, y todavía más importante, de estructuras intelectuales que atañen al ordenamiento expresivo en una cadena de sucesos 
visuales. Extensa, porque ningún otro arte en el siglo XX ha comprometido en su manifestación a mayor número de intelectuales y artistas.

La invención del cine como instrumento técnico arrastra consigo la necesidad imperiosa de crear con gran rapidez un lenguaje que le es propio y que se ajusta a ese medio absolutamente novedoso que significan las imágenes. Lo visual inventa una codificación que hasta entonces no existía. El cine se imagina a sí mismo y propone la norma que lo dice. Todo el público en general, y también los artistas, han de aprender a descifrar las claves de ese nuevo lenguaje que paulatinamente el cinematógrafo crea ajustándose a las vertiginosas necesidades de expresión que la misma herramienta requiere. Y esta necesidad de comprender un orden inédito origina igualmente herramientas intelectuales hasta entonces inexistentes.

Se trata de mecanismos que la necesidad de un vehículo visual requiere como suyos y exclusivos. Y esta técnica expresiva tendrá una incidencia en el resto de las formas del arte insospechada. Con la llegada del cine, en resumidas cuentas, surge una manera de acceder al mundo que deslumbra y acapara la atención de la cultura artística en Europa y América, y muy en particular en París, centro neurálgico cultural durante las primeras décadas del siglo XX.

El cine enseña a ver, facilita un conocimiento de las cosas propio, multiplica las posibilidades del hombre para mirar, ensanchando su capacidad espacial inmediata y reduciendo progresivamente las distancias culturales e informativas de unos continentes que se empequeñecen. Revela esa realidad material que antes, sencillamente, no existía. "El cine -explicaba el pintor Marcel Gromaire- puede transformar el pensamiento de una parte a otra del Mundo. Tiene el don de la ubicuidad y el poder de hablar directamente a las masas"1.

Enseguida artistas e intelectuales comprendieron el verdadero valor y alcance de aquello que comenzaba a surgir impetuosamente como el medio de expresión de mayor importancia para el siglo incipiente. Gromaire apunta también aspectos claves que determinarán las dimensiones que ha de alcanzar esta manifestación. Entre ellos, la influencia incalculable que las imágenes comenzaban a tener desde su función unificadora en la comunicación del pensamiento, tal y como queda latente en las reflexiones del surrealista Maxime Alexandre al hablar del cine como un fenómeno de profunda importancia en el arte de los años veinte: "Cómo hacer comprender la influencia que el cine ha tenido en nuestra imaginación, desde sus comienzos, coincidiendo con el comienzo de nuestras vidas, el estupefacto descubrimiento que supuso para nosotros"2.

Es necesario subrayar la apreciación por la cual el cine, como práctica reciente, produce y crea su propia retórica a medida que crece y se desarrolla para satisfacer sus propias necesidades de expresión. El cine ha de inventarse a sí mismo. La gran mayoría de escritores y artistas compartieron este convencimiento, y es notable el compromiso creativo que muchos de ellos emprendieron. Por otro lado, es necesario precisar de qué manera la aparición y el desarrollo comunicativo de las imágenes ha de tenerse en cuenta en los cambios estéticos y la práctica artística que se inicia en Francia con las vanguardias históricas. El cine incorpora a las competencias expresivas del arte una serie de procedimientos hasta entonces inéditos: la asociación, la secuencialidad, la elipsis y la sustantividad como sus rasgos principales.

El procedimiento por el cual dos imágenes por el hecho de reunirse y situarse una al lado de la otra sin otra razón aparente que la estricta concomitancia está en el origen del concepto de imagen. Cuando hablamos de "imagen" no nos estamos refiriendo a un aspecto icónico, sino a un método nuevo de producción de sentido por el cual la reunión de dos o más elementos heterogéneos sin ninguna relación entre sí y sin ninguna base racional que justifique ese encuentro

\footnotetext{
${ }^{1}$ Gromaire, 1919: 248-49 [Le cinéma peut transporter la pensée d'un bout à l'autre du Monde. Il a le don d'ubiquité et le pouvoir de parler directement aux foules].

2 AleXANDRE, 1968: 70 [Comment faire comprendre l'influence que le cinéma aura exercé sur notre imagination, depuis ses débuts, coïncidant avec les débuts de notre vie, la stupéfiante découverte qu'il fut pour nous].
} 
será capaz de generar significado y contenidos. La eclosión de esta manera de "leer" queda patente en el montaje cinematográfico.

El cine no nace el 28 de diciembre de 1895 con los Lumière y su proyección de la entrada del tren en la estación de la Ciotat. El cine propiamente dicho no es imagen en movimiento. La esencia del cine responde a su capacidad para significar mediante el procedimiento de asociación de imágenes que es el montaje, y para eso hay que hacer referencia al inventor del cine como lenguaje que es Griffith en la primera década del siglo XX.

La "imagen" como procedimiento no se corresponde de manera exclusiva con el séptimo arte, pero lo que consigue el cine desde las primeras películas de Griffith es sistematizar este procedimiento de producción de sentido. Por otra parte, hay que aclarar que el concepto de "asociación" remonta a finales del siglo XIX, donde fraguan las ideas y conceptos más importantes que poco después van a materializarse en las vanguardias históricas.

En 1868, en sus Cantos de Maldoror, Lautréamont describe la belleza como "la retractilidad de las garras en las aves de rapiña; o, incluso, como la incertidumbre de los movimientos musculares en las llagas de las partes blandas de la región cervical posterior; o más bien, como esa ratonera perpetua, siempre tensa por el animal atrapado, que puede cazar por sí sola, indefinidamente, roedores y funcionar, incluso, oculta bajo la paja; y, sobre todo, como el encuentro fortuito de una máquina de coser y un paraguas en una mesa de disección"”, definición que Man Ray pondrá en escena en su famosa fotografía de 1933 (fig. 1).

La gran innovación en la propuesta de Lautréamont, que va a generalizarse constituyendo uno de los fundamentos de la poética moderna, es que la imagen renuncia al vínculo construyendo su significado sobre la descarga que de ese encuentro, deliberado o fortuito, tiene lugar entre dos elementos dispares. No hay otra justificación para ese encuentro que la estricta sorpresa y la emoción estética que de ello se deriva. La noción de Lautréamont subyace en el Arte poético de Max Jacob cuando afirma en 1915 que la nueva poesía está hecha de "conclusiones imprevistas" y "asociaciones de palabras e ideas"

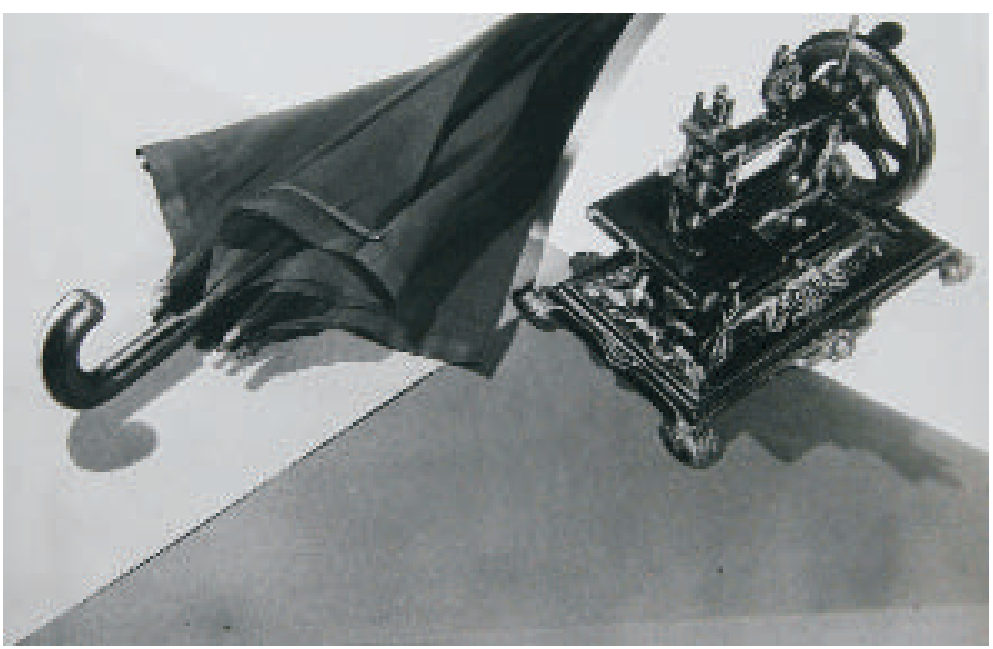

Fig. 1. Man Ray, Beau comme la rencontre fortuite, sur une table de dissection, d'une machine à coudre et d'un parapluie, 1933.

\footnotetext{
${ }^{3}$ LAUTRÉAMONT, 1953: 327 [La rétractabilité des serres des oiseaux rapaces; ou encore, comme l'incertitude des mouvements musculaires dans les plaies des parties molles de la région cervicale postérieure; ou plutôt, comme ce piège à rats perpétuel, toujours retendu par l'animal pris, qui peut prendre seul des rongeurs indéfiniment, et fonctionner même caché sous la paille; et surtout, comme la rencontre fortuite sur une table de dissection d'une machine à coudre et d'un parapluie].

${ }^{4}$ JACOB, 1987: 16 [conclusions imprévues, associations de mots et d'idées].
} 
y de forma explícita en la definición de imagen poética que Pierre Reverdy publicó en su revista Nord-Sud en 1918:

"La imagen es pura creación del entendimiento.

No puede nacer de una comparación sino de la aproximación de dos realidades más o menos alejadas.

Cuanto más alejada y certera sea la relación entre las dos realidades reunidas, más intensa será la imagen, más fuerza emotiva y realidad poética tendrá"5.

Planteamiento que vuelve a repetirse en los mismos términos, con el elemento de azar añadido, en el manifiesto surrealista de 1924 firmado por Breton y en la definición que Max Ernst propone del collage o la técnica del montaje de choque para el cine expuesta por Eisenstein en 1923 en "El montaje de atracción"6.

"Es falso, en mi opinión, pretender que el pensamiento ha relacionado dos realidades juntas. Para empezar no ha asociado nada de forma consciente. Es por el acercamiento más o menos fortuito de dos términos de donde surge una luz particular, la luz de la imagen"7.

Nos encontramos ante uno de los aspectos clave en la articulación del lenguaje del arte a partir de finales del siglo XIX, la asociación de elementos heterogéneos sin un vínculo necesario que hace saltar la emoción de la poesía en su más amplio sentido de la palabra.

En este contexto y confluencia de necesidades expresivas hay que entender la irrupción del cubismo en tanto que planteamiento estético. Entre otras muchas cosas, el cubismo responde a la necesidad de reunir en un mismo plano perceptivo secuencias temporales diversas. La linealidad narrativa es sustituida por un discurso que pretende contar la realidad de manera instantánea mediante la asociación de planos que cobran sentido en una percepción sintética. "El análisis estético serviría -respondió Juan Gris en 1925 en la revista Bulletin de la vie artistique para la encuesta "Chez les cubistes"- para disociar el mundo exterior y extraer elementos de la misma categoría. La técnica asociaría elementos formales para alcanzar la unidad, que sería sintética"8. El principio de asociación está presente en el conjunto de procedimientos expresivos de las vanguardias como uno de los recursos clave que define su lenguaje (fig. 2).

Pierre Reverdy, amigo de Juan Gris y Pablo Gargallo, y que junto a otros poetas como Max Jacob o André Salmon rechazaron siempre el apelativo de poetas cubistas, emparentaba los presupuestos estéticos de la pintura con la poesía en términos que se sitúan muy cerca de los recursos cinematográficos descritos más arriba:

"Liberar, para crear, los vínculos que las cosas tienen entre sí para acercarlas ha sido siempre el propósito de la poesía. Los pintores han aplicado este procedimiento a los objetos y, en lugar de representarlos, se han ocupado de los vínculos existentes entre ellos"9.

\footnotetext{
${ }^{5}$ REVERDY, 1975: 73 [L'image est une création pure de l'esprit. Elle ne peut naître d'une comparaison mais du rapprochement de deux réalités plus ou moins éloignées. Plus les rapports des deux réalités rapprochées seront lointains et justes, plus l'image sera forte, plus elle aura de puissance émotive et de réalité poétique].

${ }^{6}$ EISENSTEIN, 1986: pp. 181-183.

7 BRETON, 1985: p. 48-49 [Il est faux, selon moi, de prétendre que "l'esprit a saisi les rapports" de deux réalités en présence. Il n'a, pour commencer, rien saisi consciemment. C'est du rapprochement en quelque sorte fortuit des deux termes qu'a jailli une lumière particulière, lumière de l'image].

8 Juan GrIs, "Chez les cubistes", Bulletin de la vie artistique, 1925, en KAHNwEILER, 1946: 290 [L'analyse esthétique servirait à dissocier le monde extérieur pour en tirer des éléments de la même cathégorie. La technique associerait ces éléments formels pour arriver à une unité. Elle serait synthétique].

9 Pierre Reverdy, "Le cubisme poésie plastique", L'Art, febrero 1919, en Nord-Sud, Self Defence et autres écrits sur l'art et la poésie (1917-1926), 1975: 114 [Dégager, pour créer, les rapports que les choses ont entre elles, pour les
} 


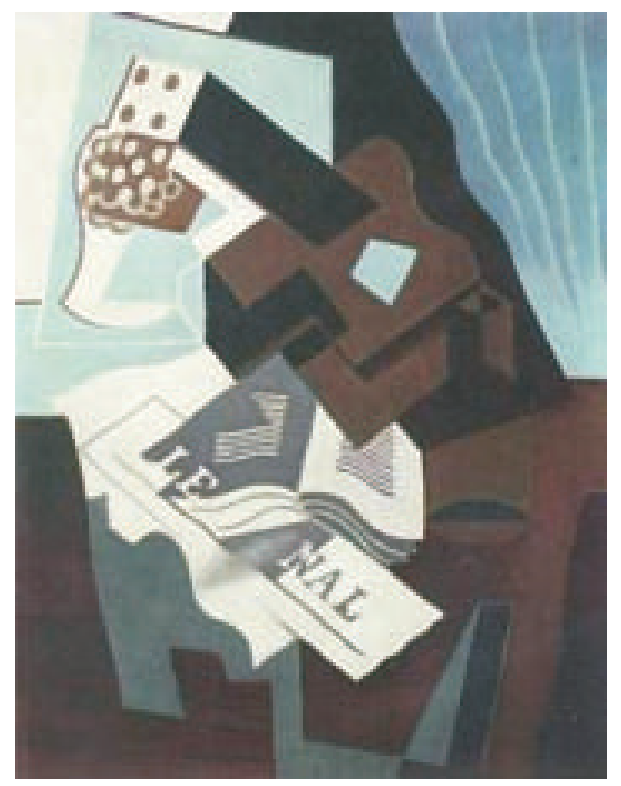

Fig. 2. Juan Gris, Bodegón con guitarra, libro y periódico, 1919.

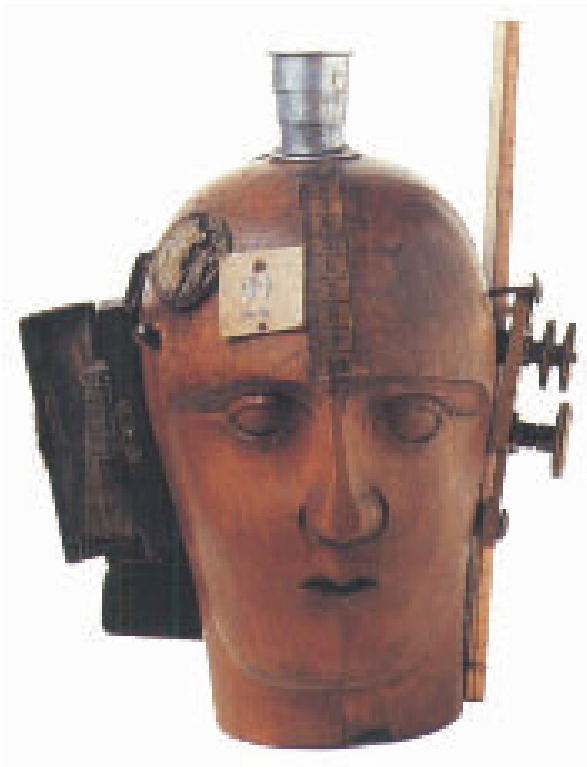

Fig. 3. Raoul Hausmann, El espíritu de nuestro tiempo, 1919.

Desde estos mismos postulados es posible explicar y entender collages escultóricos como el famoso "El espíritu de nuestro tiempo" de 1919 realizado por Raoul Hausmann, en donde una serie de elementos heterogéneos se dan cita alrededor de una cabeza de madera. Todos los elementos que configuran la obra del artista alemán no comparten entre sí otra cosa que la circunstancia de confluir en un mismo espacio significativo y esa es precisamente la razón que sienta las bases de relato. Se trata de una narración sintética dentro de un discurso espacial que se fundamenta, como señala Pierre Reverdy, en los vínculos entre los elementos más que en los elementos propiamente dichos. Es la asociación lo que hace significar más que las partes asociadas. Es la propia articulación de lenguaje lo que comunica más que el significado de las mismas palabras. Eso quiere decir "imagen", es decir, el sentido y significado de los vínculos (fig. 3).

Una parte significativa de la obra escultórica de Pablo Gargallo, particularmente sus trabajos con plantillas y chapa, responde a este mismo planteamiento: una narración lineal de planos convertida en el espacio sintético del volumen escultórico (fig. 4$)^{10}$.

El montaje de planos para crear volumen en Gargallo, atiende a esa misma voluntad de producir sentido mediante la asociación de elementos sucesivos en el tiempo que interrumpen la linealidad para configurarse en espacio (fig. 5).

Cuesta trabajo imaginar lo que significó la irrupción del cine ante los ojos deslumbrados, entusiastas, en algunos casos escépticos, de los primeros intelectuales y artistas que asistieron como testigos privilegiados al nacimiento del lenguaje visual de aquello que Ricciotto Canudo bautizó como séptimo arte. Sólo mediante una prospección en la arqueología estética e inte-

\footnotetext{
rapprocher, a été de tous temps le propre de la poésie. Les peintres ont appliqué ce moyen aux objets et, au lieu de les représenter, se sont servis de rapports qu'ils découvraient entre eux].

${ }^{10}$ Ver al respecto mi trabajo "Pablo Gargallo y el nacimiento de la modernidad. Literatura, fotografía y cine", Archivo Español de Arte, n. ${ }^{\circ} 333$, enero-marzo 2011; pp. 67-80.
} 

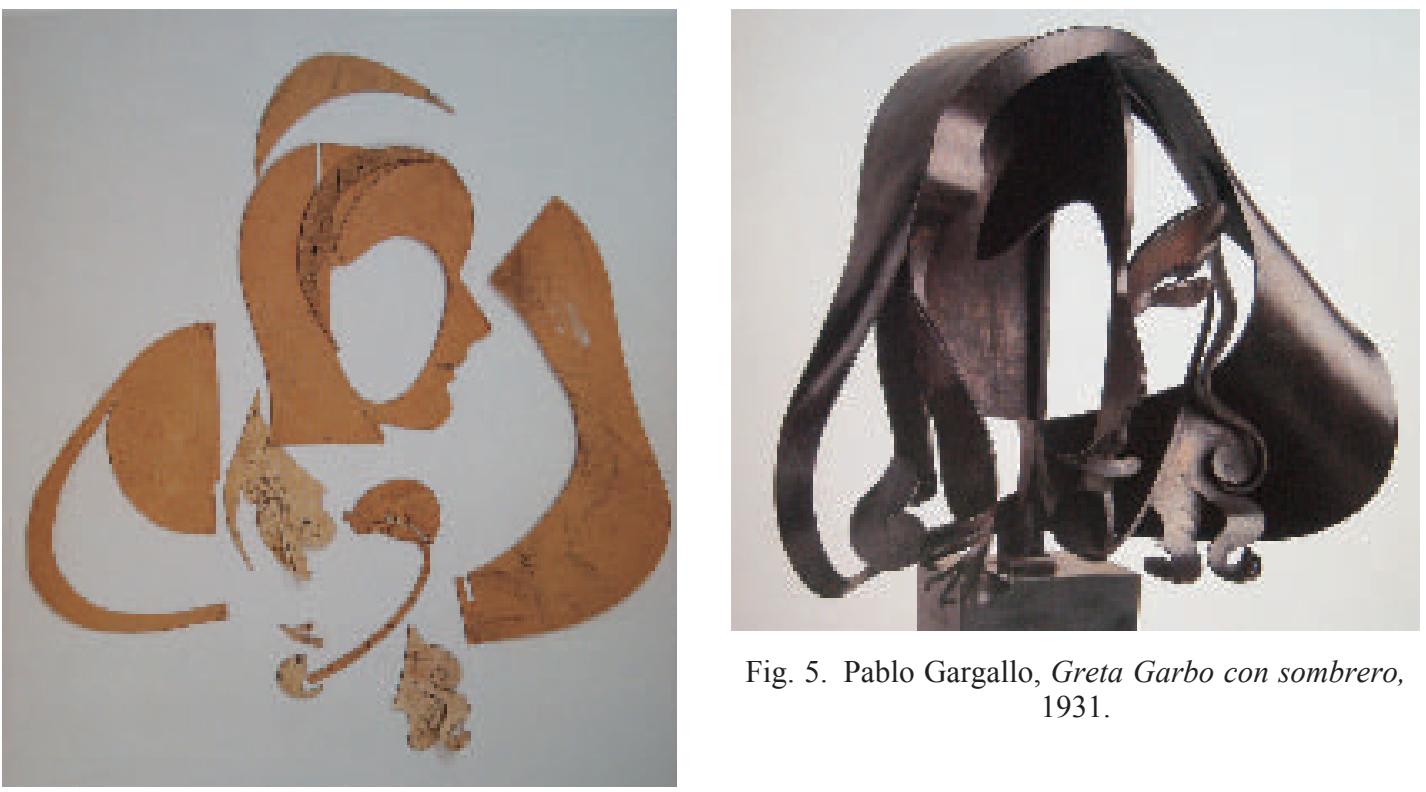

Fig. 5. Pablo Gargallo, Greta Garbo con sombrero, 1931.

Fig. 4. Pablo Gargallo, Greta Garbo con sombrero, 10 cartones recortados, 1931.

lectual de esos primeros testimonios, podemos hacernos una idea del impacto y el alcance cultural que tuvo el nacimiento del cine. El testimonio de Marcel L'herbier sobre el modo en que era percibido el primer plano, cuando el cine todavía no se había convertido en cine, es revelador:

"Un director de cine francés, Robert Péguy, ha contado en este sentido que cuando quiso montar un primer plano su productor se opuso: ¿está loco? argumentó el hombre. ¿Qué son esas gentes de las que sólo se ve la mitad? Va a hacer creer que contratamos a personas con las piernas cortadas. Se cuenta la misma anécdota sobre los comienzos de Griffith" (fig. 6) ${ }^{11}$.

Todos, como espectadores, sabemos leer hoy un primer plano. Pero no siempre fue así. Hemos de realizar un trabajo de reconstitución para hacernos una idea de las dificultades y de la agitación intelectual que supusieron estas y otras innovaciones técnicas en las conciencias artísticas de comienzos del siglo XX. "La última gran película de Marlène Dietrich -escribía el poeta André Salmón- comenzaba con la presentación de un par de piernas. Nada más que piernas. Las pantorrillas y las rodillas cortadas por un falda corta. En primer plano"12. El impacto visual del primer plano cinematográfico encuentra su traducción pictórica en el objeto como

11 Bardèche, Maurice y Brasillach, Robert: “Comment on tournait un film en 1900”, en L'Herbier, Intelligence du cinématographe, 1946: 366 [Un metteur en scène français, Robert Péguy, a d'ailleurs raconté que lorsqu'il voulu montrer des gros plans, son directeur s'y opposa: Vous êtes fou? Déclara cet homme. Qu'est-ce que c'est que ces gens dont on ne voit que la moitié? Vous allez faire croire que nous employons des cul-de-jatte. On raconte la même anecdote sur les débuts de Griffith].

12 Salom, 1932: 9 [Le dernier grand film de Marlène Dietrich commençait par la présentation d'une paire de jambes. Rien que des jambes. Les mollets et les genoux coupés par une courte jupe. En gros plan]. 


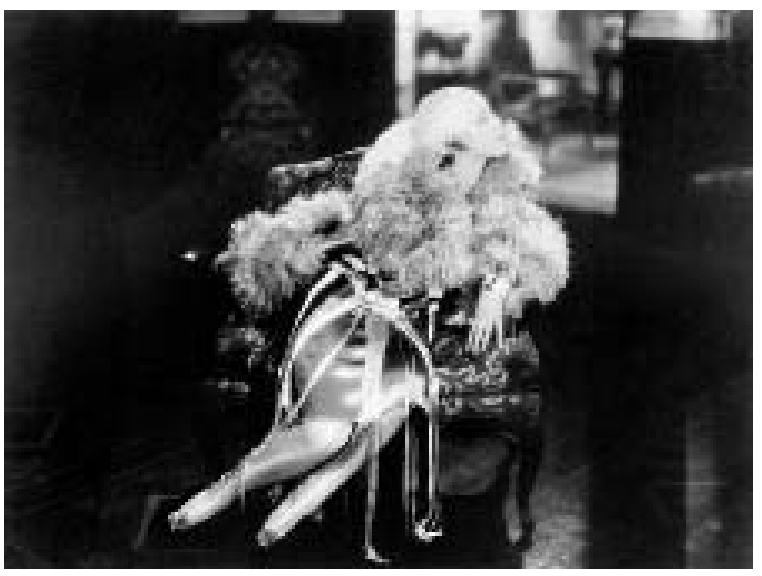

Fig. 6. Marcel L'Herbier, L'Argent, 1928.

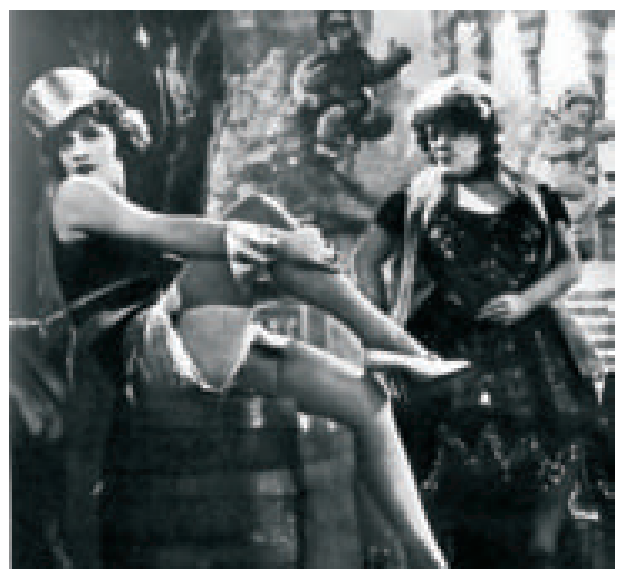

Fig. 7. Joseph von Sternberg, El ángel azul, 1930.

depositario de información en la diégesis del film, y en términos literarios será el sustantivo, en tanto que valor de significado exclusivo, la manifestación verbal de ese interés visual por elementos precisos y presentados de forma aislada (fig. 7).

"El cine -escribe Hans Richter- ha liberado por completo al objeto de su significación racional, anecdótica y simbólica para construir el film sobre el exclusivo valor plástico del objeto"13. Desde la aparición del cinematógrafo, surge con el arte de las imágenes, como respuesta a las mismas necesidades expresivas, la preocupación por entender el sentido de esas imágenes como un lenguaje que busca su propia estructura. Esta disposición entre los intelectuales de la vanguardia revela, en cualquier caso, una conciencia profunda que atañe en efecto a las fórmulas que el cine va desarrollando con el uso, se despierta enseguida entre los escritores el convencimiento de que las imágenes conforman un sistema de signos con leyes propias y mecanismos de actuación que le son exclusivos. Ciertamente, no llegarán a plantearse, como decimos, el ordenamiento y delimitación de ese sistema lingüístico, pero es importante para nosotros descubrir la conciencia, en ocasiones más intuida que confirmada, de que el cine posee unas reglas que lo convierten en un lenguaje con una articulación muy particular. El esfuerzo, en ocasiones vano, por imponer unos límites capaces de alcanzar la categoría de lengua para las bases de un sistema visual es relativamente reciente (fig. 8).

Características que se traducen en mecanismos comunes para la retórica del arte en general a partir del momento en el que el cine se impone de manera incuestionable como un medio de expresión de supremacía creciente. El primer plano se manifiesta con paroxismo en La pasión de Juana de Arco de Dreyer y constituye la base expresiva de montajes como Le phénomène de l'extase de Salvador Dalí (fig. 9).

Duchamp y su celebérrima provocación titulada Fontaine (1917), además de inaugurar lo que hoy conocemos como ready-made y "objets trouvés", supone un punto de inflexión capital en la historia del arte al desplazar el acento del objeto al sujeto. Los ready-made responden a una actitud y unos resultados visuales, fotográficos y cinematográficos, pues lo propio de la fotografía no es el objeto fotografiado sino la decisión del ojo de seleccionar en el marasmo de la realidad ese fragmento, ese objeto y no otro. Con las imágenes se inclina la balanza del lado del que mira,

13 RICHTER, 1927: 22. 


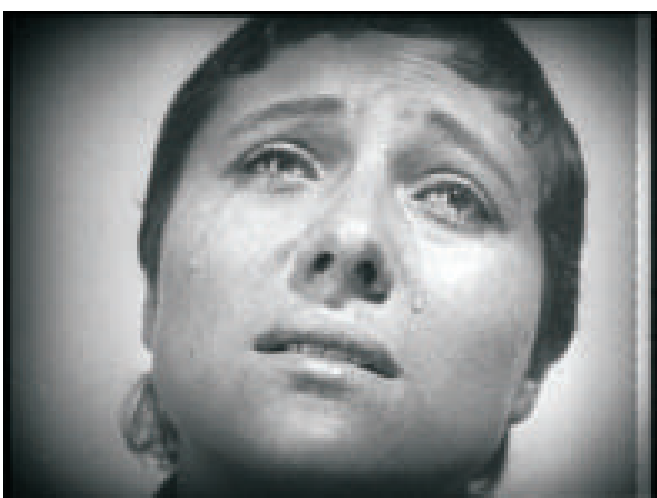

Fig. 8. Theodor Dreyer, La pasión de Juana de Arco, 1928.

Fig. 9. Salvador Dalí, Le phénomène de l'extase, 1933.

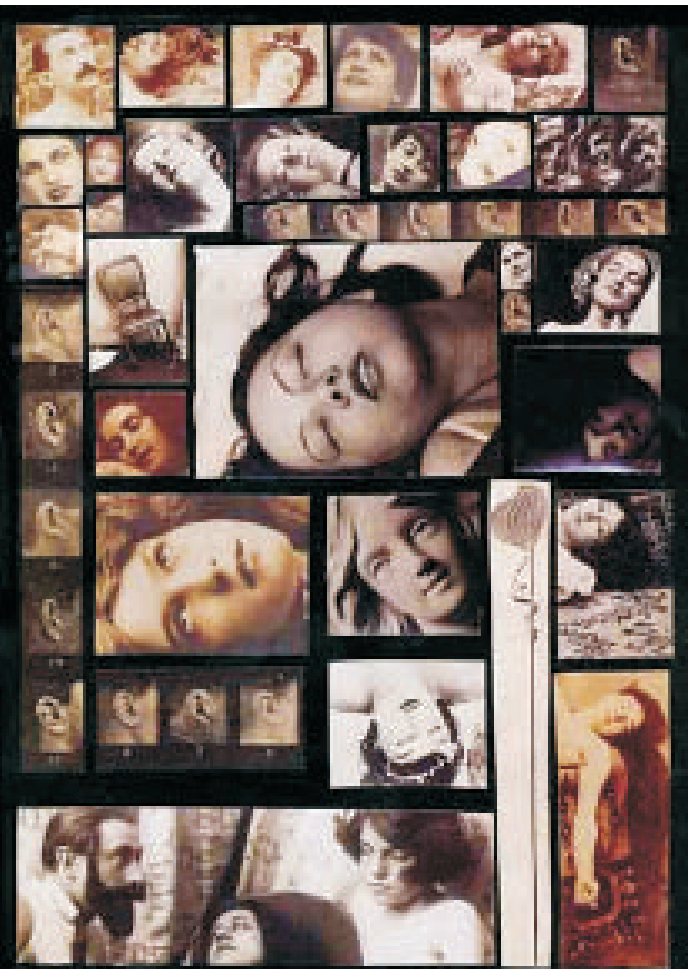

convirtiendo en arte la voluntad del artista por encima de la cosa observada. El arte se convierte en un deseo, una voluntad que en última instancia no necesita siquiera materializarse. El objeto deja paso a la mirada.

Atribuir a la asociación y al primer plano el valor y la función articulatoria de este lenguaje nuevo denota el conocimiento profundo y la realidad del empleo de estas técnicas incipientes, y de algún modo su incorporación al bagaje de recursos estilístico a la hora de hacer literatura ${ }^{14}$. Nos hallamos ante un lenguaje que acaba de nacer, y de ello son conscientes los escritores que incorporan al bagaje cultural de su época la expresividad del cine como manifestación de unos cambios muy profundos en el espíritu y la creación que comienzan con la crisis del naturalismo precedente.

Todos los receptores primeros del cine debían aprender a interpretar un lenguaje nuevo para el cine. "Necesitábamos primero aprender el alfabeto visual nosotros mismos, antes de hablar y

14 Entre los numerosos aspectos técnicos del cine que la literatura moderna hace suyos, como el primer plano traducido en sustantivos o la incorporación de fragmentos "pegados" en el texto de manera directa sin elaboración literaria o intervención del narrador, como sucede en el menú que GómEZ DE LA SERNA incorpora en El Gran hotel (1922), Barcelona, Al Monigote de papel, 1942; p. 58, el montaje se traduce en secuencias narrativas yuxtapuestas sin transición narrativa mediante elipsis dentro de la diégesis del relato, recurso puesto en práctica en novelas como Manhattan Transfer (1925) de John Dos PAssos o Berlin Alexanderplatz (1929) de DöBLIN. La bibliografía crítica sobre las relaciones entre cine y literatura es muy amplia, aborda innumerables aspectos y sigue suscitando gran interés. Ver, por ejemplo, el monográfico "Fuentes literarias del cine", Arbor, n. ${ }^{\circ}$ 741, enero-febrero 2010, o el trabajo de Jan BAETENS: La novéllisation du film au roman, lectures et analyses d'un genre hybride, Liège, Les impressions Nouvelles, 2008, sobre las novelas surgidas a partir de las adaptaciones literarias de películas. 
de creer en nuestra fuerza; y a continuación había que enseñar ese lenguaje elemental"15 confiesa el poeta Blaise Cendrars. Y es el propio cine el que ofrecía en su misma constitución las claves y el modo en el que debía adquirirse esa competencia necesaria para leer su discurso.

Se trata de un lenguaje elemental que, por otra parte, encontrará su traducción en el origen de algunos de los discursos más dispares que configuran las formas de nuestro siglo. Insistimos, una vez más, en que el cine sienta alguna de las bases que determinan la retórica que comienza alrededor de la primera guerra mundial, como se desprende de los trabajos de Léon-Paul Fargue, donde habla de alfabeto refiriéndose al desarrollo del lenguaje cinematográfico: "hasta Méliès el cine balbucea, masculla su alfabeto. Y bruscamente desaprende. Ya no se preocupa más de los medios que le van a permitir aprender a leer"16. Encontramos en ellos el punto de referencia de Méliès como hito clave en la evolución de la técnica del cine. Hay que destacar en el fragmento de Fargue la terminología que utiliza el poeta para referirse a las características formales de la imagen. Con similar referencia que Blaise Cendrars al aludir al conjunto de reglas que rigen la organización del discurso visual, el alfabeto, rasgo que se repite a lo largo del fragmento como una clave para la interpretación de los acontecimientos retóricos que tienen lugar con el cinematógrafo.

Insiste sobre la capacidad del cine para crear su universo propio de aprendizaje, que consiste esencialmente en el descubrimiento de los códigos de lectura. Una vez más el cinematógrafo propone las claves que determinan la competencia lingüística de su discurso, su lectura a medida que las mismas imágenes aprenden igualmente a expresarse. El cine descubre y enseña en una correspondencia que se dirige en ambos sentidos, complementándose. El autor realiza una crítica importantísima a la evolución del alfabeto-cine. De manera muy literaria confirma un reproche que viene repitiéndose a lo largo de todos los primeros testimonios sobre el nuevo arte: la ausencia final de compromiso del cine con una expresividad artística superior:

"Los tomavistas se perfeccionan. Se retoma el estudio serio de la fotografía, el sentimiento, las fórmulas de Descartes y las anticipaciones de Méliès. Nos zambullimos a continuación en el alfabeto; pero, porque el libro es más rico y más grande e ilustrado con caracteres, nos entristecemos, saltamos al abordaje, sin dudarlo un minuto, de la isla misteriosa de la metafísica naturalista que habíamos cuidadosamente evitado hasta entonces. Tímido ensayo de desembarque que fracasa"17

El reproche de Fargue adquiere las características de la estética naturalista, que de alguna manera representa el lado opuesto al que estaban enfrentadas las propuestas más avanzadas de la literatura de principios de siglo. Recordaremos que el inconveniente máximo que se atribuye al cine tras los primeros años de experimentación será, en efecto, caer en la anécdota renunciando a las vastas posibilidades que en un principio anunciaba. El naturalismo representa una concepción del arte imitativo frente a la radical propuesta de las primeras vanguardias para potenciar obras con absoluta independencia en el mundo exterior, al cual se suman como objetos que no sólo no imitan la realidad, sino que la enriquecen. Ese naturalismo en el cine, enfrentado a una

15 Cendrars, 1987: 37 [Mais il nous fallait d'abord apprendre l'alphabet visuel nous-mêmes, avant de parler et de croire à notre force; ensuite, il nous fallait enseigner ce langage élémentaire].

${ }^{16}$ FARgUe, 1944: 218 [Jusqu'à Méliès, le cinéma balbutie, il apprend à parler, il anonce son alphabet. Brusquement, il désapprend. Il ne s'occupe plus que des moyens qui vont lui permettre d'apprendre à lire].

17 FARgue, 1944: 218-219 [Les appareils à prises de vues se perfectionnent; on en revient à l'étude approfondie de la photographie, au sentiment, des formules de Descartes et des anticipations de Méliès. On se replonge ensuite dans l'alphabet; mais, parce que le livre est plus riche et plus grand et enluminé des caractères, on se grise, on aborde, sans même s'en douter, à l'île mystérieuse de la métaphysique naturaliste que l'on avait soigneusement évitée jusqu'alors. Essai timide de débarquement, qui échoue]. 
concepción poética de las imágenes, representa una concepción del cinematógrafo anecdótica, en la que ha renunciado a las inmensas posibilidades de expresión que ofrecía el medio, sometido a los imperativos de la industria y de una producción reducida progresivamente a films que sólo se sustentan en la narración lineal.

El fracaso del que habla este autor no es otro que el mismo que atribuye Artaud y tantos otros escritores e intelectuales a un cine que habían considerado desde un principio como la fórmula que podía renovar un lenguaje poético agotado y sin emoción. La manera en la que escritores e intelectuales, como testigos privilegiados del nacimiento de un nuevo vehículo de expresión, recibían y analizaban la expansión del cine nos informa del modo y el grado en que las imágenes influyeron en sus postulados y convencimientos estéticos. De este modo, podemos hacernos una idea aproximada del grado de presencia de una serie de preocupaciones intelectuales por alguno de los comentarios latentes intercalados en obras de cualquier índole.

Uno de los primeros intentos, si no el primero, por encontrar una sistematización en el cine pertenece a Ricciotto Canudo. Claro está, todavía no podemos hablar de lenguaje cinematográfico, pero sí es importante el objetivo de Canudo para determinar que en el cine existe un conjunto de recursos técnicos de carácter particular a las imágenes. Ricciotto Canudo se plantea este estudio desde el punto de vista de la creación de una estética cinematográfica, la cual refleja algunos de los procedimientos de los que el cine se sirve en su expresión. Para Canudo el cine es "un sistema a fin de cuentas, una concepción unitaria de aspiraciones y logros que hace que toda obra de arte nunca se presente como un fenómeno aislado, sino siempre formando parte de un todo y vinculado al alma total de un tiempo" 18 , una estética con unas reglas que dominan u ordenan el funcionamiento de ese discurso visual que es el cine. No obstante, la consideración de Canudo sobre el cine como "sistema" está encaminada en otra dirección, la de entender las diversas manifestaciones del arte como respuesta a un estímulo y unas necesidades de expresión compartidas. Esta es una de nuestras ideas claves a la hora de entender la intersección formal entre disciplinas artísticas diversas.

En lugar de existir una influencia directa del cine en el arte, encontramos unos puntos comunes que atienden a planteamientos estéticos, precisamente, en cuanto resultado de una necesidad común, sin olvidar nunca lo específico de cada uno de los lenguajes, y sobre todo, y más importante, la primacía del primero en el descubrimiento de ciertas formas que le son propias y que posteriormente se reciclaron en algunos casos dando lugar a nuevas formas literarias como el cinepoema o la cinenovela ${ }^{19}$.

Más adelante el poeta utiliza una imagen para explicar el arte del cine en la que revela de manera intuitiva lo que años después se convertirá en verdadera reflexión sobre la escritura visual: "El film no es a fin de cuentas más que la más inmediata exaltación emotiva de la escritura de la luz" ${ }^{20} \mathrm{Y}$ unas cuantas páginas más atrás Canudo realiza una afirmación importante que atañe, en efecto, a toda expresión de acuerdo con su idea de sistema: "El cine inventa de nuevo la experiencia de la escritura" 21 , es decir, reconoce el papel que el cine desempeña en una nueva

\footnotetext{
18 CANUdo, 1927: 13 [Un "systhème" en somme, une conception unitaire des aspirations et des réalisations, qui fait que toute œuvre d'art apparaît comme un phénomène jamais isolé, mais toujours partie d'un ensemble, lié à l'âme totale d'un temps].

${ }^{19}$ En "Literatura visual en las vanguardias francesas", Madrid, Thélème, Revista Complutense de Estudios Franceses, Vol. 25, Publicaciones Universidad Complutense de Madrid, 2010, pp. 9-19, realizo un repaso de los trabajos más importantes pertenecientes resultados de la transformación de guiones cinematográficos jamás realizados y reescritos y adaptados en obras con carácter literario.

${ }^{20}$ CANUdO, 1927: 26 [le film, n'est en définitive que l'exaltation la plus immédiatement émouvante de l'écriture de la lumière].

${ }^{21}$ CANUdo, 1927: 34 [Le Cinéma recommence, en vérité, l'expérience de l'écriture].
} 
concepción de la escritura, donde los mecanismos que las imágenes introducen, muy pronto son apropiados y puestos en la práctica por la pintura, la escultura o la poesía.

Este contacto estrecho con el cine favoreció un proceso de integración de algunas de esas técnicas aludidas que el cine introducía en el medio creativo, con el consiguiente planteamiento y riqueza expresiva que se posó en los recursos literarios, pictóricos o escultóricos a los que hacíamos referencia más arriba, los cuales entraban, en aquellos momentos, en un periodo de cambios profundos que facilitó, sin duda, el grado y la importancia de estas intersecciones formales.

La comprensión, acompañada del análisis del nuevo medio que se les imponía irremediablemente, configuró un clima de permeabilidad creadora por unas circunstancias históricas y estéticas compartidas. Existe una influencia real en la creación de nuevos hábitos de comprensión intelectual, nuevas dimensiones espaciales y temporales, y una actitud distinta ante los mismos acontecimientos de la vida con la aparición del cine. Encontramos en escritos de autores diversos en el panorama creativo del París de los años veinte el eco de una identificación inmediata entre cine y pensamiento. Esto refleja una actitud permeable, por parte de artistas, escritores e intelectuales, hacia la organización de un lenguaje que se impone como alternativa a otros ya existentes, e identificado con los procesos del intelecto en el pensamiento del hombre. Cuando Antonin Artaud da cuenta de su experiencia en la escritura del guión para la película de Germaine Dulac La coquille et le clergyman (1928) está presente este convencimiento creciente de que el cine, los procedimientos del cine, se encuentran identificados estrechamente con la fuente del pensamiento (fig. 10).

"He comprendido al escribir el guión de La Coquille et le clergyman, que el cine poseía un elemento propio, verdaderamente mágico, verdaderamente cinematográfico, y que nadie hasta entonces había pensando aislar. Este elemento perfectamente identificable y vinculado a las imágenes participa de la vibración misma y del nacimiento inconsciencia y profundo del pensamiento" 22 .

En la reflexión de Artaud se insinúan ya dos cosas importantes que inmediatamente aparecerán en otros autores con mayor claridad: por un lado, la sospecha de que no sólo hay una aproximación entre las estructuras del cine y del pensamiento, sino que el primero es un reflejo del funcionamiento del cerebro. Por otro, que ese reflejo del pensamiento que propone el cine está relacionado con un impulso inconsciente, lo que lo vincula con una de las tradiciones más importantes del siglo XX, como es el nacimiento de la subjetividad radical con el hallazgo del inconsciente por el psicoanálisis, la surrealidad, y el mundo de los sueños.

Ricciotto Canudo pone de relieve de forma clara la vinculación de las imágenes

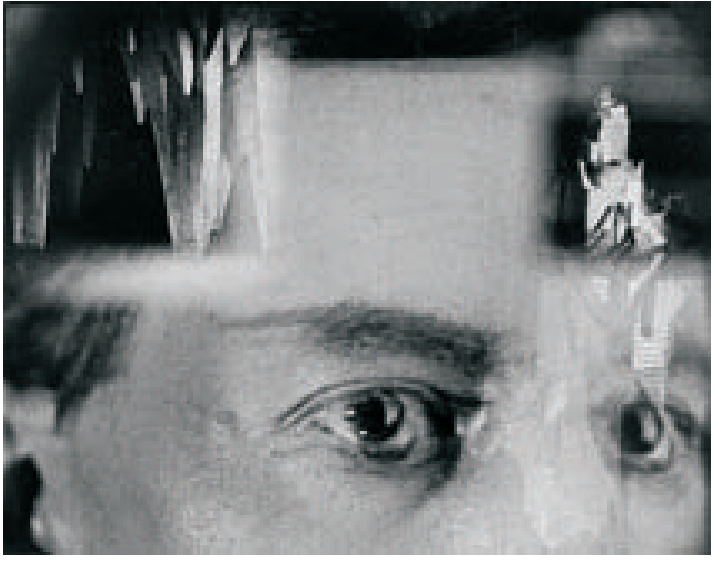

Fig. 10. Germaine Dulac, La coquille et le clergyman, 1928.

22 ARTAUd, 1970: 90 [J'ai estimé en écrivan le scénario de La Coquille et le clergyman, que le cinéma possédait un élément propre, vraiment magique, vraiment cinématographique, et que personne jusque là n'avait pensé à isoler. Cet élément distinct de toute espèce de représentation attaché aux images participe de la vibration même et de la naissance inconsciente, profonde de la pensée].

Arch. esp. arte, LXXXV, 339, JULIO-SEPTIEMBRE 2012, 251-264, ISSN: 0004-0428 
con el mundo del sueño y del pensamiento. Canudo establece un puente de unión específico entre el cine y la realidad inconsciente. Hay que hacer notar, una vez más, que el poeta resalta el dominio exclusivo del cine, el valor irremplazable que poseen las imágenes: "Uno de los dominios del cine será el de lo inmaterial o, más precisamente, del subconsciente. La visión de recuerdo o del pensamiento de los personajes ya había tentado a más de un guionista"23. Explica Canudo que formas como el recuerdo y el pensamiento encuentran en el cine una manera favorable y adecuada de transmisión, y para ello enumera diferentes modos de expresar tanto el recuerdo, el sueño o el pensamiento a través de técnicas que sólo al cine pertenecen.

Las palabras desaparecen para dejar paso a superposiciones en origen torpes, deformaciones, imágenes veladas, juegos de luz o de intensidad de contrastes. Y no obstante, lo más destacable de Ricciotto Canudo es su observación con respecto a las proporciones de realidad que siempre y en todo momento conserva el cine, aun en imágenes que pretenden reflejar la realidad inconsciente del pensamiento: "Dar una imagen subconsciente, más allá de la realidad inmediata, puede vestir de blanco pálido al padre de Hamlet, pero permanecerá siempre dentro de las proporciones exactas de la realidad cotidiana" ${ }^{24}$. El análisis de Canudo insiste sobre el carácter de realidad que siempre conserva el cine. Recordemos su explicación sobre el contenido de realidad de incluso las imágenes más inverosímiles. Incluso los sueños en el cine tienen una correspondencia innegable con las cosas.

El poeta surrealista Robert Desnos identifica el deseo de soñar con el de asistir al sueño de una película, pues los estímulos que acontecen en ambas manifestaciones, la humana y la artística, comparten un misterio particular. Ya no se trata de la lógica, claro está, ni siquiera de una incomprensión fácil, sino de algo mucho más importante y que insiste de manera constante sobre la vertiente sistemática de realidad que las imágenes proponen en cada visión. Los sueños en el cine se ven y se recuerdan siempre, no escapan al llegar la vigilia:

"El amor y el gusto por el cine tiene que ver con el deseo de soñar. A falta de la aventura espontánea que nuestros párpados dejarán escapar al despertar, vamos a las salas oscuras en busca del sueño artificial y tal vez el excitante capaz de poblar nuestras noches desiertas. /.../ Ya no se trata de ninguna lógica, de construcción clásica ni de complacencia ante la incomprensión del público, sino de cosas vistas, de un realismo superior que abre un nuevo dominio a la poesía y al ensueño"25.

Se trata de un realismo superior, es decir, de una suprarrealidad o surrealidad. Y es la materialidad de la presencia virtual de las imágenes lo que cuenta en el cine, el ofrecimiento de posibilidades todavía insospechadas.

El carácter de ensoñación del cine, en lugar de alejarlo de la realidad y oscurecer las formas del mensaje y el mensaje mismo, lo que hace es aproximarlo todavía más al sentimiento de materialidad de la visión e incluso del mundo. En lo que a esto respecta, lo visual llega a convertir acciones inverosímiles en acciones aceptables e incluso necesarias: tal es el caso de formas de vida y comportamientos sociales, o determinadas propagandas ideológicas y políticas ${ }^{26}$.

23 CANUdo, 1927: 41-42 [Un des domaines du cinéma, sera celui de l'immatériel, ou, plus exactement, du subconscient. La vision du souvenir ou de la pensée des personnages avait déjà tenté à maint écraniste].

${ }^{24}$ CANUDO, 1927: 42 [Donner une image subconsciente, au delà de la réalité immédiate, il peut habiller de blanc vague le père d'Hamlet, mais il restera toujours dans les proportions exactes de la réalité quotidienne].

${ }^{25}$ DESNOS, 1966: 104 [Du désir du rêve participe le goût, l'amour du cinéma. A défaut de l'aventure spontanée que nos paupières laisseront échapper au réveil, nous allons dans les salles obscures chercher le rêve artificiel et peut-être l'excitant capable de peupler nos nuits désertées. /.../Il ne s'agit plus de logique, de construction classique, ni de flatterie à l'incompréhension publique, mais de choses vues, d'un réalisme supérieur, puisqu'il ouvre un nouveau domaine à la poésie et au songe].

${ }^{26}$ El reciente ensayo del fotógrafo de la agencia Magnum Ferdinando SciannA, Etica e fotogiornalismo, nos recuerda el compromiso ineluctable de imágenes y verdad, así como la responsabilidad de quien las produce, algo que parece obviarse en el ámbito de la fotografía artística. 
El cine, su digamos realidad, sus digamos construcciones imaginarias mediante movimientos de cámara, su falacia a fin de cuentas, viene a convertirse en un acto radical de fe. La intensidad con la que arranca el cine se sustenta en el suministro de creencia incondicional que exige a sus receptores. Cualquier imagen para este cine analógico pertenece y proviene de la realidad, incluso las artificiales, las imaginarias, escenarios, decorados. Todas ellas son el reflejo incuestionable de una existencia, y es en este ámbito donde soñar adquiere formas visibles, el que seduce definitivamente el espíritu creador del arte.

Lo que proviene del cine, pues, atiende a las manifestaciones formales de la inteligencia. Resulta expresión de unas razones visuales, de esquemas particulares. Proyección o reflejo del pensamiento, y por supuesto creador, productor de lenguaje. Jean Epstein pone en tela de juicio, no sin cierta ironía, la dimensión artística del cine cuando afirma que "podría ser que no fuera un arte (el cine) sino otra cosa, pero mejor. Se diferencia al grabar mediante el cuerpo el pensamiento"27. Cuando el cineasta afirma que un rostro no es nunca fotogénico pero su emoción sí, hay que entender por emoción el efecto de ese rostro traducido en imágenes. Esa es la esencia de la fotogenia y la intensidad que adquiere cualquier imagen, de la fotografía o del cine. Ese rostro, cualquier otro rostro o un objeto cobran una relevancia notable a partir del momento que se ve retenido en un negativo, revelado o en proyección.

René Clair, plantea, poco tiempo después, la concomitancia e incluso competencia entre imágenes y pensamiento en términos de sucesión, en ocasiones con la rapidez y falta de transiciones articulatorios de la mente que se abandona a un fluir indeterminado, cuando afirma que "El pensamiento compite en velocidad con el paso de las imágenes. Pero se retrasa y, vencido, queda sorprendido. Se rinde. La pantalla, nueva mirada, se impone a la mirada pasiva" ${ }^{28}$. René Clair se sirve de la fórmula de la derrota para poner de relieve el lugar insustituible que ocupan las imágenes en la geografía intelectual de los primeros años del siglo XX. Con el nacimiento del cine aparece un elemento que supera a todos los demás, al menos en un estado inmediato, en acomodación de los procedimientos que emplea y esos acontecimientos que tienen lugar en la interioridad del hombre (fig. 11).

No hay que olvidar, por otra parte, que el monólogo interior, como sistema extendido y desarrollado de una práctica literaria que persigue el reflejo de la interioridad del ser humano, nace y se perfecciona de manera paralela al cine, que por definición, tal y como hemos visto, es acogido igualmente y con primacía como la manera ideal de reflejar la realidad oculta del pensamiento, el subconsciente, el sentimiento interior, la palabra interior.

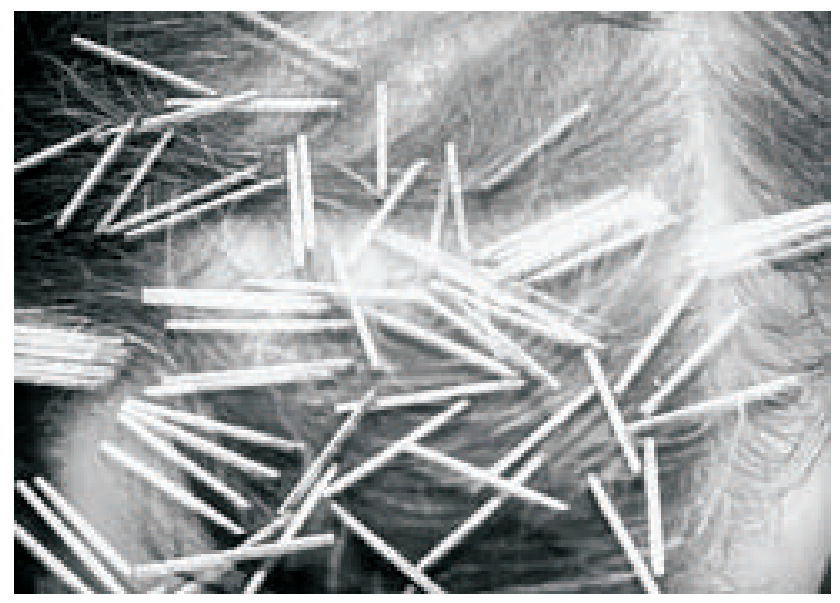

Fig. 11. René Clair, Entr'act, 1924.

27 EpStein, 1974: 100 [Il se pourrait qu'il ne soit pas un art [le cinéma], mais autre chose, mais mieux. Cela le distingue qu'à travers le corps il enregistre la pensée].

28 Clair, 1925: 13 [La pensée rivalise de vitesse avec le défilé des images. Mais elle retarde et, vaincue, subit la surprise. Elle s'abandonne. L'écran, nouveau regard, s'impose à notre regard passif]. 
La fotografía y el cine daban por concluida la ciencia positiva que situaba al hombre como medida y centro del universo. Ambas tecnologías ponían en tela de juicio la fiabilidad en los sentidos. La fotografía, por un lado, se revelaba como un instrumento capaz de ver más y mejor que el ojo humano. Las experiencias del Muydbridge y Marey hacían evidente que era posible confiar en la percepción ocular. El cine, por otro lado, era el resultado de una ilusión, un "trompe l'oeil", nunca mejor dicho. La medida del universo deja de ser el hombre para ceder su puesto a la máquina. Ya no vemos con nuestros ojos, vemos a través de aparatos que convierten la realidad en imágenes. Si "los humanos somos aquello que de nosotros dicen nuestras imágenes" ${ }^{29}$, afirma Félix de Azúa en su Autobiografía sin vida, las imágenes de la fotografía y el cine son el producto por primera vez en la historia de la representación del mundo de una visión maquinista. Ahora cobra sentido pleno el concepto de "artificio" en tanto que constructo de aquello que las máquinas son capaces de ver y por tanto imaginar. La literatura, la pintura, la escultura que nacen a la par de la fotografía y el cine son el reflejo de ese cambio de roles. El arte convertido en una máquina de ver.

\section{BIBLIOGRAFÍA}

Alexandre, Maxime, Mémoires d'un surréaliste, Paris, La Jeune Parque, 1968.

Aragon, Louis, Les collages, Paris, Hermann, 1965.

Artaud, Antonin, Euvres complètes. Scenari, Paris, Gallimard, 1970.

Azúa, Félix, Autobiografía sin vida, Barcelona, Mondadori, 2010.

Breton, André: Manifestes du surréalisme, Paris, Gallimard, 1985.

Canudo, Ricciotto, L'Usine aux images, Genève, Office Central d'Édition, 1927.

Cendrars, Blaise, Aujourd'hui 1917-1929, Paris, Denoël, 1987.

Clair, René, "Rythme", Les Cahiers du mois, n. ${ }^{\text {ss }}$ 16/17, 1925, p. 13.

Desnos, Robert, Cinéma (Textes réunis et présentés par André Tchernia), Paris, Gallimard, 1966.

Eisenstein, Sergei, The Film Sense, London, Faber \& Faber, 1986.

Epstein, Jean, Ecrits sur le cinéma, Paris, Seghers, 1974.

Fargue, Léon-Paul, Lanterne magique, Paris, Laffont, 1944.

Jacob, Max, Art poétique, Paris, L'Eloquent, 1987.

Kahnweiler, Daniel-Henry, Juan gris, sa vie, son æuvre, ses écrits, Paris, Gallimard, 1946.

L'Herbier, Marcel, Intelligence du cinématographe, Paris, Editions Corrêa, 1946.

Lautréamont, Les Chants de Maldoror, en Ouvres complètes, Paris, José Corti, 1953.

Reverdy, Pierre, Nord-Sud, Self Defence et autres écrits sur l'art et la poésie (1917-1926), Paris, Flammarion, 1975.

Richter, Hans, "Mouvement", Schema, febrero 1927, p. 22.

Salom, André, Marlène Dietrich, Paris, La Nouvelle Librairie Française, 1932 (Coll. Hollywood).

Scianna, Ferdinando, Etica e fotogiornalismo, Milano, Electra, 2010.

Fecha de recepción: 15-IV-2011

Fecha de aceptación: 21-XI-2011

29 AzÚA, 2010: 35. 